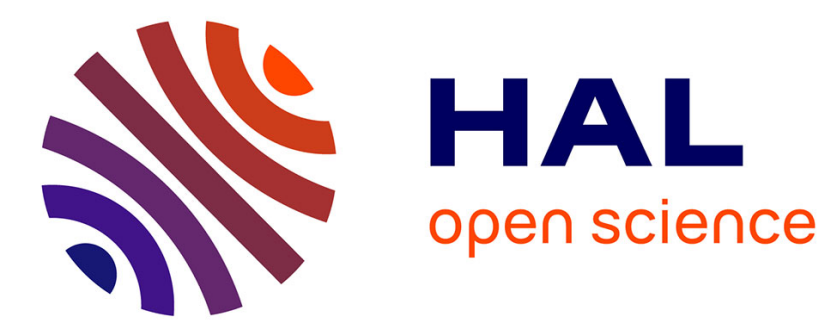

\title{
Tell Me What You See, I Will Tell You What You Remember
}

Florian Marchal, Sylvain Castagnos, Anne Boyer

\section{To cite this version:}

Florian Marchal, Sylvain Castagnos, Anne Boyer. Tell Me What You See, I Will Tell You What You Remember. 24th Conference on User Modeling, Adaptation and Personalization (UMAP'16), Jul 2016, Halifax, Canada. hal-01305030

\section{HAL Id: hal-01305030 \\ https://hal.inria.fr/hal-01305030}

Submitted on 2 May 2016

HAL is a multi-disciplinary open access archive for the deposit and dissemination of scientific research documents, whether they are published or not. The documents may come from teaching and research institutions in France or abroad, or from public or private research centers.
L'archive ouverte pluridisciplinaire HAL, est destinée au dépôt et à la diffusion de documents scientifiques de niveau recherche, publiés ou non, émanant des établissements d'enseignement et de recherche français ou étrangers, des laboratoires publics ou privés. 


\section{Tell Me What You See, I Will Tell You What You Remember}

\author{
Florian Marchal \\ LORIA - Université de Lorraine \\ Campus Scientifique, B.P. 239 \\ 54506 Vandœuvre - France \\ florian.marchal@loria.fr
}

\author{
Sylvain Castagnos \\ LORIA - Université de Lorraine \\ Campus Scientifique, B.P. 239 \\ 54506 Vandœuvre - France \\ sylvain.castagnos@loria.fr
}

\author{
Anne Boyer \\ LORIA - Université de Lorraine \\ Campus Scientifique, B.P. 239 \\ 54506 Vandœuvre - France \\ anne.boyer@loria.fr
}

\begin{abstract}
Recommender systems usually rely on users' preferences. Nevertheless, there are many situations (e-learning, e-health) where recommendations should rather be based on their memory. So as to infer in real time and with low involvement what has been memorized by users, we propose in this paper to establish a link between gaze features and visual memory. We designed a user experiment where 24 subjects had to remember 72 images. In the meantime, we collected 18,643 fixation points. Among other metrics, our results show a strong correlation between the relative path angles and the memorized items.
\end{abstract}

\section{Keywords}

Learner modeling; Gaze data; Visual memory; Recall

\section{INTRODUCTION}

There are many areas where recommendations based on users' preferences are not sufficient. As an example, a recent study on Massively Open Online Courses (MOOCs) ${ }^{1}$ shows that only $6.5 \%$ of users really achieve them. The length of the course appears to be the critical factor, since it is the same for every users. In this context, recommending resources that fit the active user's learning curve, in addition to their interests, may increase their satisfaction and the completion rate of the courses.

E-health is also a domain where it can be interesting to focus on memory. This would for instance allow to early diagnose neuro-degenerative diseases, by comparing the behavior of patients with the behavior of a healthy population. Nevertheless, modeling the memory of users in a traditional way can be very time-consuming and requires a high user involvement.

In this paper, we investigate the possibility to infer the

${ }^{1}$ Katy Jordan, University of Texas, 2013 may
http://techcrunch.com/2014/03/03/study-massive-online-
courses-enroll-an-average-of-43000-students-10-completion/

Permission to make digital or hard copies of part or all of this work for personal or classroom use is granted without fee provided that copies are not made or distributed for profit or commercial advantage and that copies bear this notice and the full citation on the first page. Copyrights for third-party components of this work must be honored. For all other uses, contact the owner/author(s).

UMAP'16 July 13-17, 2016, Halifax, NS, Canada

(C) 2016 Copyright held by the owner/author(s).

ACM ISBN 978-1-4503-4370-1/16/07 . .\$15.00

DOI: http://dx.doi.org/10.1145/2930238.2930265 memorized items through gaze data. Within the frame of recommenders, eye-tracking systems are mainly used to infer user preferences [6], to evaluate the accuracy of a recommender system [4], or to evaluate users' learning strategy [1]. Some works investigated the link between gaze data and memory, but most of them focus on the recognition process [5]. We propose here to use gaze features to model what has been recalled by users.

Section 2 offers a quick overview of the literature as regards eye-tracking usages to model cognitive processes. Section 3 is dedicated to the presentation of our experiment. Section 4 presents the analysis of the data and the results.

\section{RELATED WORK}

While most of works aim at understanding users' behavior from gaze data [8], Steichen et al. [9] followed eye movements to infer users' characteristics, such as perceptual speed and working memory. There are two main methods of accessing memory: recognition and recall. Recognition is the mental process which consists in comparing and associating a current and past stimuli. Recall involves to remember a stimulus which is not physically present. In cognitive neuroscience, most of works are dedicated to recognition [5]. As an example, Borkin et al. [2] studied the memorability of charts, using the eye-tracking to monitor how users recognize them. In this paper, we carry out an on-going research on the way to predict what is recalled by users from gaze features. Papers focusing on recall include Bondareva et al. [1] who estimate the quality of users' learning process from gaze data, and Steichen et al. [9] who explore gaze patterns through differential sequence mining. However, these papers involve the creation of predefined Areas Of Interest (AOIs), which can hardly be applied generally. Thus, we expect to extend this latter work by finding correlations between gaze features and memorized items, without the use of predefined AOIs.

\section{EXPERIMENT SETUP}

Our hypothesis is the following:

H1. The analysis of gaze features can reveal which items are recalled during human-computer interactions.

As this is a work-in-progress, our first step consists in studying if one or several of the gaze features are correlated with the memorization of items. In this section, we present the experiment we developed to validate this assumption. We took inspiration from Maxcey and Woodman [7] to show users a set of 72 images. Images were drawn from a set of 1,395 real-world objects [3], subdivided into 93 categories 


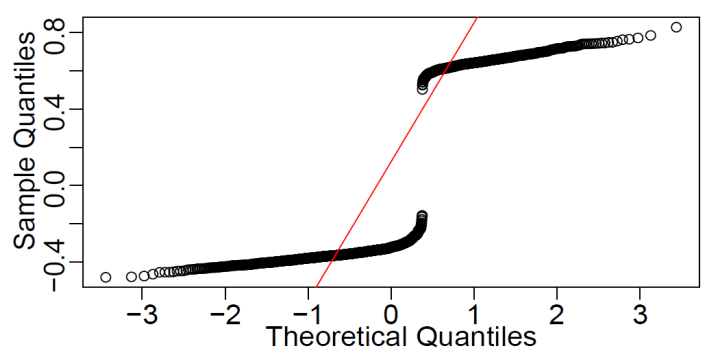

Figure 1: Difference between data and normal distribution

containing 15 items. Categories were chosen for their strong salience. For each user, we randomly selected 12 categories, and 6 items per category. During a first step, images were presented one after another in a random order. Participants were instructed to study details on each picture for a later memory test. They were told that the test would require very detailed information, and that remembering only the category would not help. Each image was displayed during $5 \mathrm{~s}$, interleaved by a $500 \mathrm{~ms}$ center fixation cross. After a short break, participants were instructed to describe on a sheet all the images they can remember from the first step, with no limit of time. Finally, they were asked to match their answers with memorized items by browsing the 72 images on a single page. The correct images have been categorized as "remembered", and all the others as "not remembered".

A Tobii X1 Light was used to monitor the subjects' eye movements and the software Tobii Studio was used to record the gaze data and transform them into fixations.

Twenty-four members participated in the experiment (10 females). They were between 23 and 62 years old (Mean $=$ 32). Participants had normal or corrected-to-normal visual acuity.

\section{DATA AND STATISTICAL ANALYSIS}

Our data analysis proceeds in 3 steps. First, we gathered the fixation data from Tobii Studio. Then, we reconstructed the saccades from the transitions between the fixations. Finally, we dynamically built AOIs from fixation points, for each user and each image, with a simple clustering algorithm (DBSCAN). Let us notice that there were no predefined AOIs (such as specific regions of the images). Our AOIs only rely on the way users look at the images.

For all the users, a total of 18 gaze features (such as the sum, mean or standard deviation of fixation duration, or the saccade length) were computed and tested to find a potential correlation with the fact that images have been recalled or not. We first used an analysis of covariance (ANCOVA) to test data from all the images and all the users. However, the distribution of the data did not follow a normal form, as shown in Figure 1.

Thus, we chose to apply a permutation test. The latter is a non-parametric test that fits better with our nonnormal distribution. The Table 1 summarizes the subset of gaze features that have a strong correlation with the fact of memorizing items. The sum of relative path angles and the number of fixations appear to be very good predictors of the memorization process, with respective residual sum of squares of 0.95 and 0.70 . These results are significant at
Table 1: Results of the permutation test

\begin{tabular}{|c|c|c|c|}
\hline Features & R Sum Sq & $\operatorname{Pr}($ Prob) & \\
\hline Sum of Relative Path Angles & 0.95 & $<2 \mathrm{e}-16$ & **** \\
\hline Number of Fixations & 0.70 & $<2 \mathrm{e}-16$ & **** \\
\hline SD of Relative Path Angles & 0.57 & 0.06209 & \\
\hline Length of 1st Fixation & 0.23 & 0.11083 & \\
\hline SD of Absolute Path Angles & 0.21 & 0.51579 & \\
\hline SD of Saccade Length & 0.33 & 1.00000 & \\
\hline
\end{tabular}

a 0.99 level, as shown in the third column of Table 1.

\section{CONCLUSION AND PERSPECTIVES}

Results showed that there is a direct link between some gaze features and the memorization of images. This reinforces our conviction that it will be possible to predict what the users remember, by using the gaze features. Among perspectives, we aim at building a model that can predict efficiently the memorization and adapt recommendations on these predictions.

\section{REFERENCES}

[1] D. Bondareva, C. Conati, R. Feyzi-Behnagh, J. M. Harley, R. Azevedo, and F. Bouchet. Inferring learning from gaze data during interaction with an environment to support self-regulated learning. In Artificial Intelligence in Education, pages 229-238, 2013.

[2] M. A. Borkin, Z. Bylinskii, N. W. Kim, C. M. Bainbridge, C. S. Yeh, D. Borkin, H. Pfister, and A. Oliva. Beyond Memorability: Visualization Recognition and Recall. IEEE Transactions on Visualization and Computer Graphics, 22(1):519-528, Jan. 2016.

[3] T. F. Brady, T. Konkle, G. A. Alvarez, and A. Oliva. Visual long-term memory has a massive storage capacity for object details. Proceedings of the National Academy of Sciences, 105(38):14325-14329, 2008.

[4] L. Chen and P. Pu. Eye-tracking study of user behavior in recommender interfaces. In User Modeling, Adaptation, and Personalization, pages 375-380. 2010.

[5] D. E. Hannula, C. L. Baym, D. E. Warren, and N. J. Cohen. The Eyes Know: Eye Movements as a Veridical Index of Memory. Psychological Science, 23(3):278-287, 2012.

[6] W. Lu and Y. Jia. Inferring User Preference in Good Abandonment from Eye Movements. In J. Li and Y. Sun, editors, Web-Age Information Management, number 9098 in Lecture Notes in Computer Science, pages $457-460.2015$.

[7] A. M. Maxcey and G. F. Woodman. Forgetting induced by recognition of visual images. Visual Cognition, 22(6):789-808, 2014.

[8] J. N. Sari, R. Ferdiana, P. I. Santosa, and L. E. Nugroho. An eye tracking study: exploration customer behavior on web design. pages 69-72, 2015.

[9] B. Steichen, M. M. Wu, D. Toker, C. Conati, and G. Carenini. Te, Te, Hi, Hi: Eye gaze sequence analysis for informing user-adaptive information visualizations. In User Modeling, Adaptation, and Personalization, pages 183-194. 2014. 